\title{
Ambient Pressure Hydrodesulfurization of Refractory Sulfur Compounds in Highly Sensitive -Reactor Platform Coupled to a Time-of-Flight Mass Spectrometer
}

Christoffersen, Ann-Louise N.; Bodin, Anders; Elkjær, Christian F.; Sørensen, Jakob Ejler; Kibsgaard, Jakob; Chorkendorff, Ib

Published in:

Journal of Physical Chemistry C

Link to article, DOI:

10.1021/acs.jpcc.7b11089

Publication date:

2018

Document Version

Peer reviewed version

Link back to DTU Orbit

Citation (APA):

Christoffersen, A-L. N., Bodin, A., Elkjær, C. F., Sørensen, J. E., Kibsgaard, J., \& Chorkendorff, I. (2018). Ambient Pressure Hydrodesulfurization of Refractory Sulfur Compounds in Highly Sensitive -Reactor Platform Coupled to a Time-of-Flight Mass Spectrometer. Journal of Physical Chemistry C, 122(3), 1699-1705. https://doi.org/10.1021/acs.jpcc.7b11089

\section{General rights}

Copyright and moral rights for the publications made accessible in the public portal are retained by the authors and/or other copyright owners and it is a condition of accessing publications that users recognise and abide by the legal requirements associated with these rights.

- Users may download and print one copy of any publication from the public portal for the purpose of private study or research.

- You may not further distribute the material or use it for any profit-making activity or commercial gain

- You may freely distribute the URL identifying the publication in the public portal 


\title{
Ambient Pressure Hydrodesulfurization of
}

\section{Refractory Sulfur Compounds in Highly Sensitive}

\author{
$\mu$-Reactor Platform Coupled to a Time-of-Flight
}

Mass Spectrometer

Ann-Louise N. Christoffersen ${ }^{1}$, Anders Bodin ${ }^{1}$, Christian F. Elkjærr ${ }^{2}$, Jakob E. Sørensen ${ }^{1}$, Jakob Kibsgaard ${ }^{1}$, Ib Chorkendorff ${ }^{1, *}$

${ }^{1}$ Department of Physics, Technical University of Denmark, Fysikvej, Building 312 DK-2800 Kgs. Lyngby, Denmark

${ }^{2}$ Haldor Topsøe A/S, Haldor Topsøes Allé 1, DK-2800 Kgs. Lyngby, Denmark 


\begin{abstract}
Tightened restrictions call for cleaner transportation fuels to minimize environmental and societal problems caused by the presence of sulfur in transportation fuels. This emphasizes the need for new and better catalysts in the field of hydrodesulfurization (HDS), which aims at removing the refractory sulfur from different petroleum streams mostly found in the form of the alkyl-substituted dibenzothiophenes ( $\beta$-DBTs). In this work we demonstrate how a setup dedicated to testing minute amounts (ng) of well-defined catalytic systems in $\mu$-reactors can be used in the gas phase HDS of the model compounds DBT and 4,6dimethyldibenzothiophene (4,6-DMDBT) and the reaction pathways revealed by time-offlight mass spectrometry. Specifically, we investigate HDS of DBT and 4,6-DMDBT on mass-selected Pt nanoparticles, and show that only the direct desulfurization (DDS) products are formed. The setup is a means to bridge the gap between structural characterization of model catalysts and their related activity in the HDS of DBT and 4,6-DMDBT.
\end{abstract}




\section{INTRODUCTION}

Environmental concern combined with the unfortunate health related effects caused by the presence of sulfur compounds in transportation fuels have led to tightened legislation, demanding more efficient hydrodesulfurization (HDS) catalysts ${ }^{1,2}$. Industrial HDS is a highpressure catalytic process conducted at elevated temperatures in excess of molecular hydrogen to form $\mathrm{H}_{2} \mathrm{~S}$ and hydrocarbons ${ }^{3-6}$. The difficulties in producing ultra-low sulfur diesel (ULSD) increase with the need for processing increasingly heavier feedstocks with high concentrations of alkyl-substituted dibenzothiophenes ( $\beta$-DBTs), which are known to be the most refractory sulfur-containing compounds found in crude oil ${ }^{7-9}$.

Especially when the alkyl groups are located in the $4^{\text {th }}$ and $6^{\text {th }}$ position, the sulfur atom is sterically hindered ${ }^{10-12}$, and reducing the total sulfur content to the sub ppm level remains a challenge. Designing catalysts that are able to spatially access the sulfur atom is therefore key to finding better and more efficient catalysts for producing essentially "sulfur-free” diesel fuel $^{13,14}$, and DBT and 4,6-dimethyldibenzothiophene (4,6-DMDBT) are therefore often used as model molecules in HDS studies ${ }^{15,16}$.

Mass-selected nanoclusters and nanoparticles deposited onto well-defined substrates have gained popularity as model catalysts ${ }^{17-23}$. Such models tested under controlled conditions represent a simplification of the complex industrial catalytic process, and may provide useful and crucial insight into the elementary steps of a catalytic reaction, especially when combined with surface sensitive characterization techniques ${ }^{24,25}$. Extensive density functional theory (DFT) and scanning tunneling microscopy (STM) studies on such clusters have revealed the adsorption mechanism of DBT and 4,6-DMDBT on well-defined $\mathrm{MoS}_{2}$ based model systems ${ }^{26,27}$ as well as the structure and promoter effects of Co and $\mathrm{Ni}^{14,28,29}$. These atoms have been found to mostly decorate the edges of the $\mathrm{MoS}_{2}$ basal planes, resulting in 
hexagonally truncated particle shapes, where especially the brim structure is of catalytic interest $^{30-34}$. The detailed structural insight provided by this type of studies has hitherto not been directly linked to the catalytic activity of model catalysts in the HDS of DBT and 4,6DMDBT. Supported catalysts, on the other hand, provide a good basis for activity measurements, but these are however very heterogeneous with $\mathrm{MoS}_{2}$ crystals of different shape and size $\mathrm{e}^{35}$ which hamper the ability to link activity to a specific structure.

a)

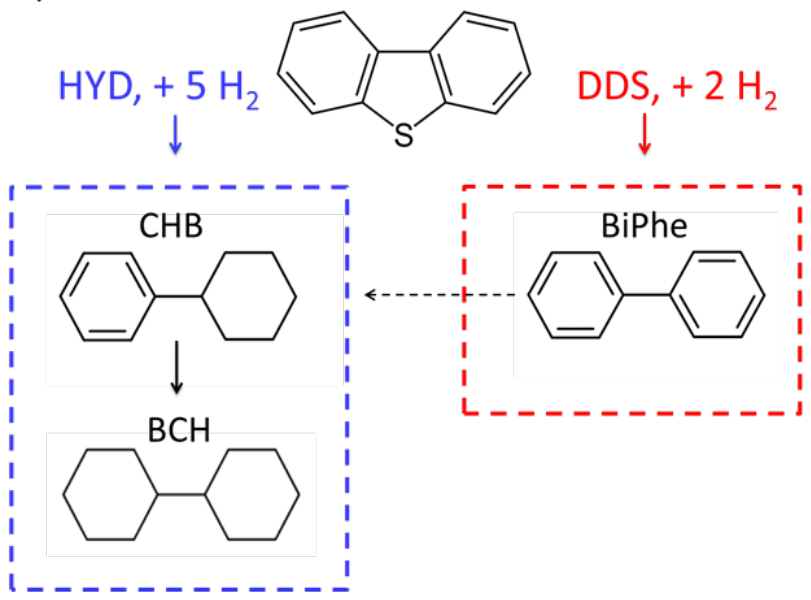

b)

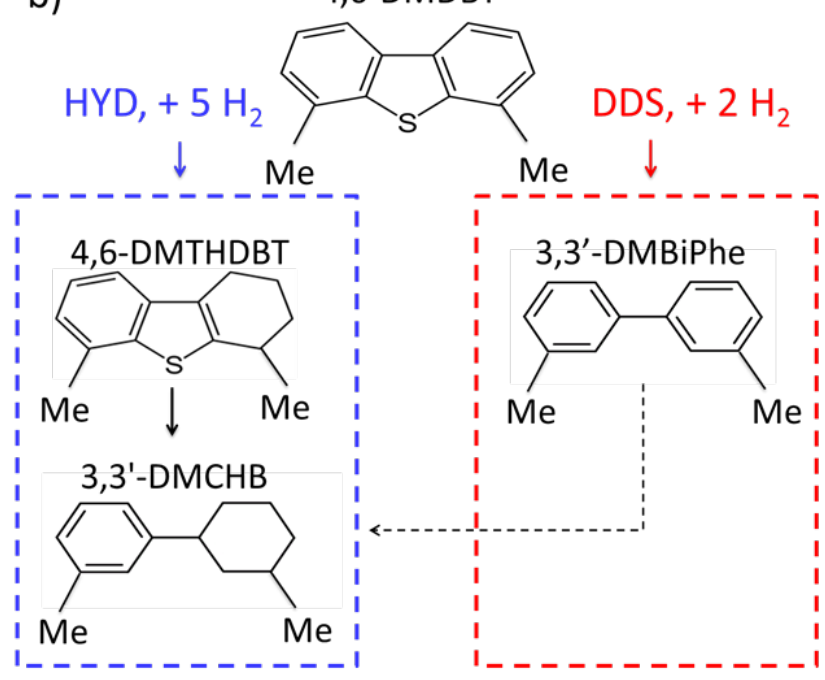

Figure 1. Reaction pathways of DBT (a) and 4,6-DMDBT (b). The direct desulfurization (DDS) pathway produces biphenyl (BiPhe) and 3,3'-dimethylbiphenyl (3,3'-DMBiPhe) respectively. The hydrogenation (HYD) pathway produces cyclohexylbenzene (CHB) and 3,3'-dimethylcyclohexylbenzene (3,3'-DMCHB) respectively.

Under the industrial HDS of DBT and 4,6-DMDBT, it is well-accepted that two different reaction pathways exist ${ }^{36-39}$, as seen in Figure 1. The hydrogenation (HYD) pathway of DBT and 4,6-DMDBT produces cyclohexylbenzene (CHB) and 3,3'-dimethylcyclohexylbenzene (3,3’-DMCHB), respectively, whereas the direct desulfurization (DDS) occurs by hydrogenolysis of the C-S bonds followed by sulfur extrusion to form biphenyl (BiPhe) and 3,3-dimethylbiphenyl (3,3'-DMBiPhe), respectively ${ }^{13,40,41}$. It is well-accepted that DBT mainly reacts through the DDS pathway, and is typically observed to adsorb on sulfur vacancies formed at both corners and edges of $\mathrm{MoS}_{2}$ nanoparticles, which are highly accessible sites for this molecule. The sterically hindered 4,6-DMDBT, on the other hand, 
mainly reacts through the HYD pathway, since the position of the methyl groups makes it complicated to adsorb through the sulfur atom ${ }^{8,13,37}$.

With the work presented here, we attempt to bridge the gap between ambient pressure measurements and surface sensitive techniques by controlled catalytic measurements of small amounts of very well-defined and uniform catalyst. To achieve this goal we have developed a setup dedicated to testing minute amounts of catalyst in the gas phase HDS of DBT and 4,6DMDBT at ambient pressure. A specially designed $\mu$-reactor platform coupled to a time-offlight mass spectrometer (TOF-MS) enables high sensitivity and data acquisition with high temporal resolution of 200 ps and a mass resolution of $m / \Delta m=2500$. In order to focus on the technical aspects of this setup, we present measurements on Pt, which is an active hydrogenation catalyst and at the same time represents a simpler case than the more complex $\mathrm{MoS}_{2}$-based catalysts ${ }^{38,42}$. Monitoring the entire range of products enables us to link specific structures to specific products, hence elucidate the prevailing reaction pathway.

\section{THE EXPERIMENTAL SETUP}

The experimental setup consists of four main parts as shown in Figure 2. 1) The reactant dosing zone features two compound sources containing DBT and 4,6-DMDBT, respectively, enabling back-to-back activity measurements of both molecules. This allows for a detailed comparison between the relative reaction rates of the HDS of DBT and 4,6-DMDBT and can be a helpful means to gain insight into the similarities and differences in products and formation and reaction pathways on a given catalyst. 2) Catalytic conversion takes place in the $\mu$-reactor platform and the outlet gas is directed through a narrow capillary into 3) a specially designed heat traced ionization zone which enables the use of 4) the TOF-MS, which is used for gas detection and analysis. 


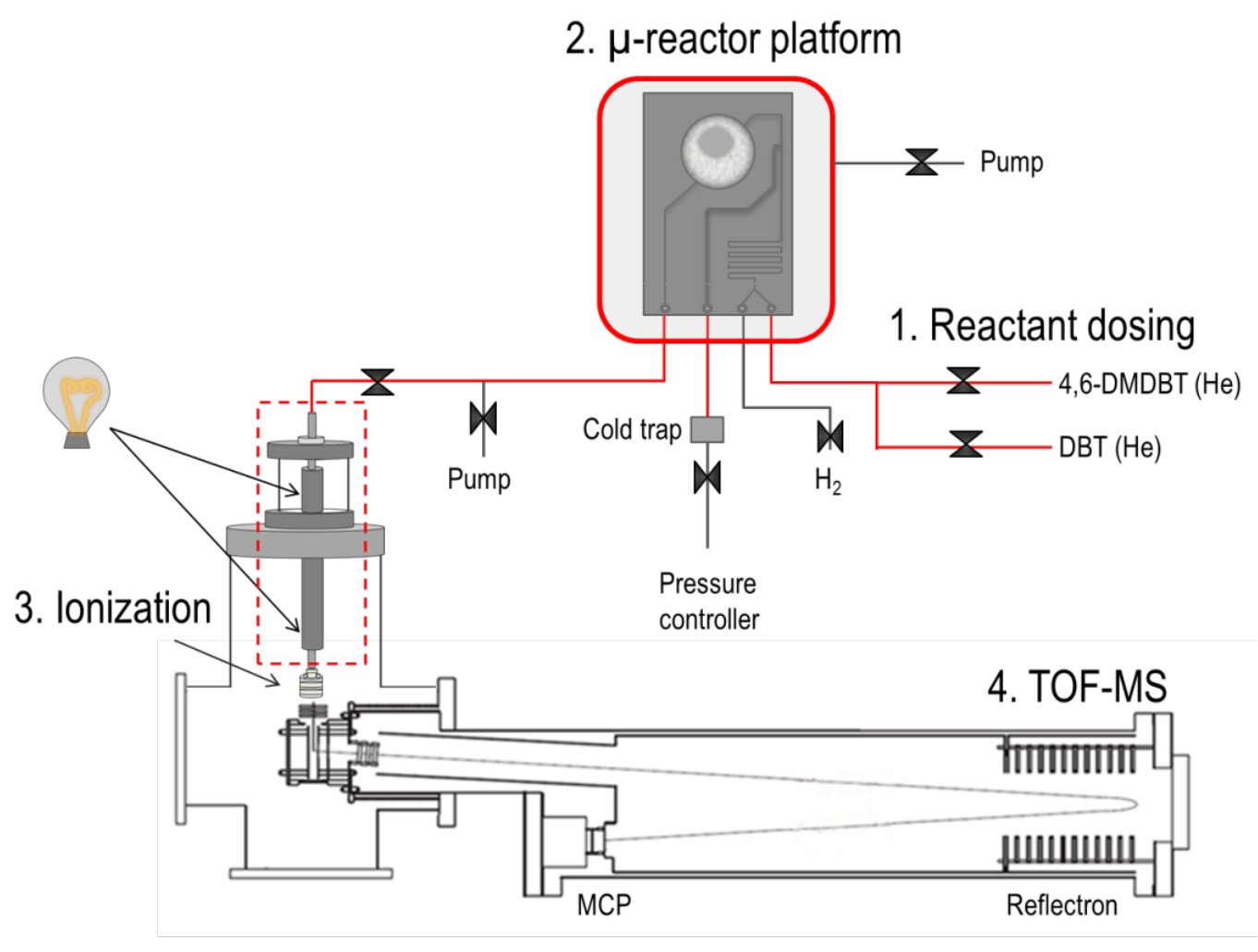

Figure 2. The experimental setup consists of four main parts. 1) The reactant dosing zone, 2) the $\mu$-reactor platform, 3) an ionization area and 4) the time-of-flight mass spectrometer (TOF-MS). The red lines represent heating.

2.1. Reactant dosing. The setup is designed so that HDS of DBT and 4,6-DMDBT can be performed back to back. Both compounds are put in homemade compound sources made from all metal and CF fittings. At room temperature the model compounds are solid crystals with vapor pressures well below $5 \times 10^{-4} \mathrm{mbar}^{43,44}$ so heating is required in order to release a sufficient amount at ambient pressure. The compound sources and valves are therefore equipped with heating tapes and thermocouples. Helium (He) is used as a carrier gas that only leaves a simple contribution in the mass scan and does not interfere with the cracking patterns of the relevant compounds. A constant flow is directed through the compound source and it is assumed that the He gas is saturated by DBT or 4,6-DMDBT, respectively, up to the vapor pressure at the given source temperature ${ }^{43}$. The entire system is heated and held at a constant temperature of $130{ }^{\circ} \mathrm{C}\left(150^{\circ} \mathrm{C}\right.$ in the case of 4,6-DMDBT $)$, and importantly, the temperature 
of the reactant dosing zone is kept well below this at $110{ }^{\circ} \mathrm{C}\left(140{ }^{\circ} \mathrm{C}\right.$ in the case of 4,6 DMDBT), in order to avoid condensation and clogging of DBT/4,6-DMDBT in pipes and valves.

2.2. The $\mu$-reactor platform. Catalytic measurements are performed in a specially designed silicon based $\mu$-reactor sealed with a Pyrex lid by anodic bonding ${ }^{45}$. It features a reaction chamber volume of approximately $240 \mathrm{nl}$, which allows minute amounts of catalysts to be tested (from $10 \mathrm{ng} / \mathrm{cm}^{2}$ to several thousands of $\mathrm{ng} / \mathrm{cm}^{2}$ ) ${ }^{46}$, typically in the form of a thin film of a single layer of particles deposited directly on the bottom of the reaction chamber which consist of $\mathrm{SiO}_{2}$. In other words, the system offers an ideal platform for testing model catalysts. Two inlets are combined and gas is mixed by diffusion in a meander structure. Most of the inlet flow never enters the reaction chamber, but is directed through an outlet to a turbo pump, where a cold trap is capturing the sulfur compounds. Only a very small fraction of the passing gas flow is supplied to the reactor, where an integrated capillary outlet ensures probing of $\sim 5 \times 10^{14}$ molecules $\mathrm{s}^{-1}$ at 1 bar. This makes it possible to direct the entire reaction zone volume into a mass spectrometer, thereby offering a high sensitivity ${ }^{45,47,48}$. An integrated Pt thin film on the backside of the silicon chip enables ohmic heating and the temperature is monitored by thermocouples mounted directly on top of the reactor. The reactor is mounted on a stainless steel manifold and sealed by Kalrez O-rings. Such materials are not entirely tight and in order to completely avoid contamination by the surrounding ambient gasses, the $\mu$-reactor is placed inside a containment volume, which is pumped by a roughing pump to obtain vacuum. The containment volume is heated along with the rest of the system to $130{ }^{\circ} \mathrm{C}$.

2.3. Ionization. The capillary outlet is connected to a stainless steel tube which is separated from the ionization zone by a valve - see “ionization”, Figure 2. This part is constantly heated, even when not running experiments. The backside of the valve facing the ionization 
zone has been modified so that an aluminum tube continues into the ionization zone. The aluminum tube is extended by an additional Al block with the same inner diameter as the tube. The block features two $150 \mathrm{~W}$ light bulbs and a thermocouple which enable heating from the valve to a commercial ionization source used for QMS, purchased from Pfeiffer. In this manner the gas enters axially through a spring mounted ceramic fitting in a gas-tight design ionization unit and is especially well-suited for small volumes of sample gas. To optimize the MS signal, the ion source is placed as close as possible to a series of entry Einzel lenses inside the TOF-MS, in order to maximize sensitivity.

2.4 TOF-MS. The time-of-flight is designed as an orthogonal mass spectrometer which has been assembled from modules purchased from Jordan TOF Products, Inc ${ }^{48}$. The ionized gas molecules are pushed from the ionization zone into the flight tube by a repelling voltage of + $800 \mathrm{~V}$ at a frequency of $4000 \mathrm{~s}^{-1}$. A liner voltage of $\sim-2500 \mathrm{~V}$ accelerates the ions further before they are deflected $7^{\circ}$ and focused. The reflectron mode increases the effective flight length of the ions thus also the resolution. Finally, the ions are directed towards the micro channel plate (MCP) detector - see “TOF-MS”, Figure 2. Whenever a pulse of $+800 \mathrm{~V}$ is initiated, a multiple-event digitizer (MCS6A) is notified and starts counting the number of ions that has reached the MCP (signal intensity) within a predefined scan length (the x-axis), only limited by the pulse frequency of $250 \mu \mathrm{s}\left(4000 \mathrm{~s}^{-1}\right)$. Complete mass spectra can therefore be produced every $250 \mu$ s but since the number of counts is proportional to the time frame in which they have been iterated, 60 seconds are preset in this work, corresponding to $2.4 \times 10^{5}$ iterations. The peak intensities are proportional to concentration and data is therefore presented as integrated peak areas of the base peak of the compounds in question normalized to counts.

\section{EXPERIMENTAL SECTION}


3.1 Sample preparation. The sample was prepared in a Multiprobe XP ultra-high vacuum system from Omicron Nanotechnology (now Scienta Omicron) with a typical chamber pressure of $1 \times 10^{-11}$ mbar. In this system, the reaction chamber of the $\mu$-reactor was cleaned prior to deposition by sputtering with $1 \mathrm{keV} \mathrm{Ar}^{+}$for 45 minutes with a sample current of 0.8 $1.3 \mu \mathrm{A}$ using an Omicron ISE 10 sputter ion source. The sample current is as measured at a bias of $+48 \mathrm{~V}$ and not corrected for secondary emissions. Before and after deposition of nanoparticles, the cleanliness and elemental composition of the sample was verified using a combination of low-energy ion scattering spectroscopy (ISS) and X-ray photoelectron spectroscopy (XPS) coupled to an Omicron NanoSAM 7 channel energy analyzer. Minute contaminations of Sn on the verge of the detection limit of XPS were identified with ISS due to the high surface sensitivity of this technique. For ISS, $1 \mathrm{keV} \mathrm{He}^{+}$ions were rastered in a $1 \times 1 \mathrm{~mm}^{2}$ area using an Omicron ISE 100 fine focus ion gun. XPS was done using a SPECS XR 50 X-ray gun using a Mg Ka source with $240 \mathrm{~W}$ power.

The nanoparticles were synthesized by an ultra-high vacuum (UHV) nanoparticle source with a typical base pressure of $1 \times 10^{-10}$ mbar (Nanobeam 2011 from Birmingham Instruments Inc.) coupled to the Multiprobe XP. As sketched in Figure 3, particles are formed by magnetron sputtering of a platinum target (99.99\% purity, Kurt J. Lesker Company) followed by gas-phase aggregation. The formed particles exit through a small aperture into a differentially pumped UHV region halting further aggregation and interaction by undergoing a super-sonic expansion. The beam of charged particles is then filtered by mass in a lateral time-of-flight mass filter with mass resolution ${ }^{49} \mathrm{~m} / \Delta m=20$ before being deposited on a sample in the adjacent Multiprobe XP chamber. Samples with nanoparticle diameters of $6 \mathrm{~nm}$ were prepared using around 0.08 mbar pressure in the aggregation zone with an $\mathrm{Ar} / \mathrm{He}$ ratio of $8: 1$ by filtering for particles of mass $1,500,000 \mathrm{amu}$. The conversion between particle size and particle mass was made assuming spherical particles. 
The neutralization current measured on the sample during deposition was integrated to a total charge of $36.4 \mathrm{nC}$. With the mass setting on the mass filter, this corresponds to a total mass of $(36.4 \mathrm{nC} / 1.602 \mathrm{e}-19 \mathrm{C}) \times 1.5 \mathrm{e} 6 \mathrm{amu} \times 1.66 \mathrm{e}-24 \mathrm{~g} / \mathrm{amu}=566 \mathrm{ng}$. In the $\mu$-reactor this corresponds to a loading of $720 \mathrm{ng} / \mathrm{cm}^{2}$.

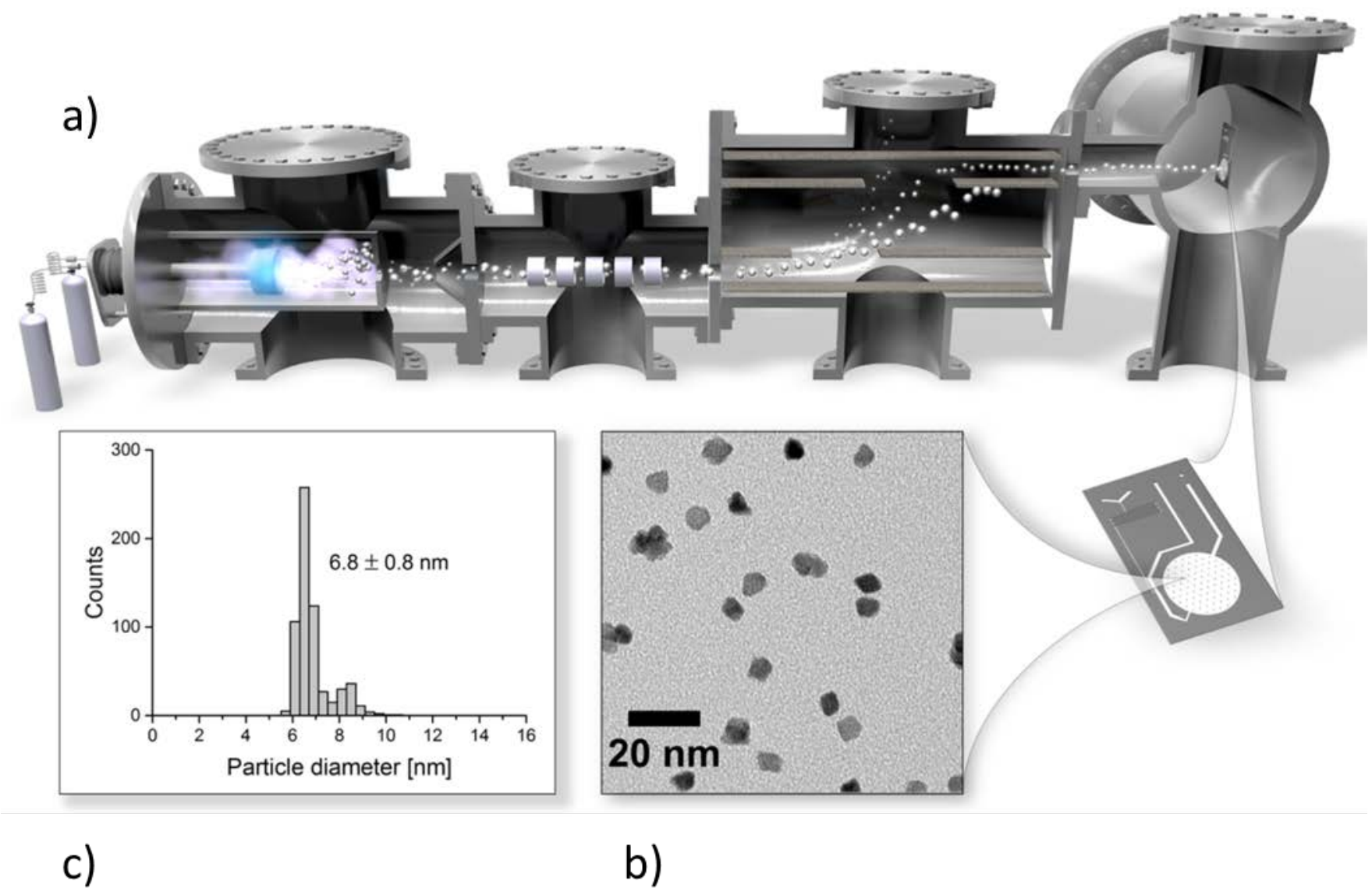

Figure 3. The nanoparticle source (Nanobeam 2011) where the Pt nanoparticles have been synthesized. The nanoparticles are deposited directly into the $\mu$-reactor in the adjacent chamber (Multiprobe XP). b) TEM image of deposited 6 nm diameter Pt particles. c) Actual 6 nm particle size distribution obtained from TEM images.

Transmission electron microscopy was used to obtain a size distribution of the nanoparticle sizes by using the same deposition conditions as for the $\mu$-reactor on a copper grid covered with lacey carbon. TEM images were acquired in a FEI Tecnai T20 G2 transmission electron microscope and analyzed using ImageJ software. The size distribution found this way is assumed to be representative of the $\mu$-reactor sample disregarding the difference between 
substrates. The size distribution in Figure 3c exhibits a second small peak around $8.5 \mathrm{~nm}$. These are due to a fraction of particles carrying two elemental charges instead of a single charge. For the mass filter, particles of double mass and two charges will thus be indistinguishable from the desired single mass/single charge particles. The distribution is skewed further by particles landing on top of each other as well as having non-spherical shapes. The shapes resemble those seen in previous studies using the same technique, where the nanoparticles exhibit polycrystallinity ${ }^{50}$. After deposition, the reactor was sealed by anodic cold bonding to prevent the particles from sintering ${ }^{45,51}$.

3.2. Catalyst activity test. The reactor was mounted and pumped down through the main outlet (pressure controller) and capillary outlet. Mass scans were initiated and recorded every second minute and the TOF valve was opened. A He (DBT/4,6-DMDBT) flow of $2 \mathrm{ml} / \mathrm{min}$ and 800 mbar was initiated and heating of the containment volume followed. Once the inside of the containment volume reached a temperature of approximately $130^{\circ} \mathrm{C}\left(150^{\circ} \mathrm{C}\right.$ in the case of 4,6-DMDBT), the compound source valves were heated as well. The DBT (or 4,6DMDBT) source was heated subsequently and once the temperature was stable around 110 ${ }^{\circ} \mathrm{C}\left(140{ }^{\circ} \mathrm{C}\right.$ for 4,6-DMDBT) and the TOF signal stopped increasing, a $\mathrm{H}_{2}$ flow of $1 \mathrm{ml} / \mathrm{min}$ was initiated (see supplementary information for TOF overview scan before addition of $\mathrm{H}_{2}$, Figure S1 and S2).

Activity measurements were conducted at 800 mbar over a temperature range from 140-380 ${ }^{\circ} \mathrm{C}$. Each temperature step of $15^{\circ} \mathrm{C}$ was kept for 30 minutes.

\section{RESULTS AND DISCUSSION}

Figure 4 and Figure 5 show the results of the HDS of DBT and 4,6-DMDBT. Representative sections of the full mass scans are shown in Figure 4 and for both DBT and 4,6-DMDBT the 
only products observed were BiPhe and 3,3'-DMBiPhe, respectively. This indicates that only the DDS reaction pathway prevails in both cases.
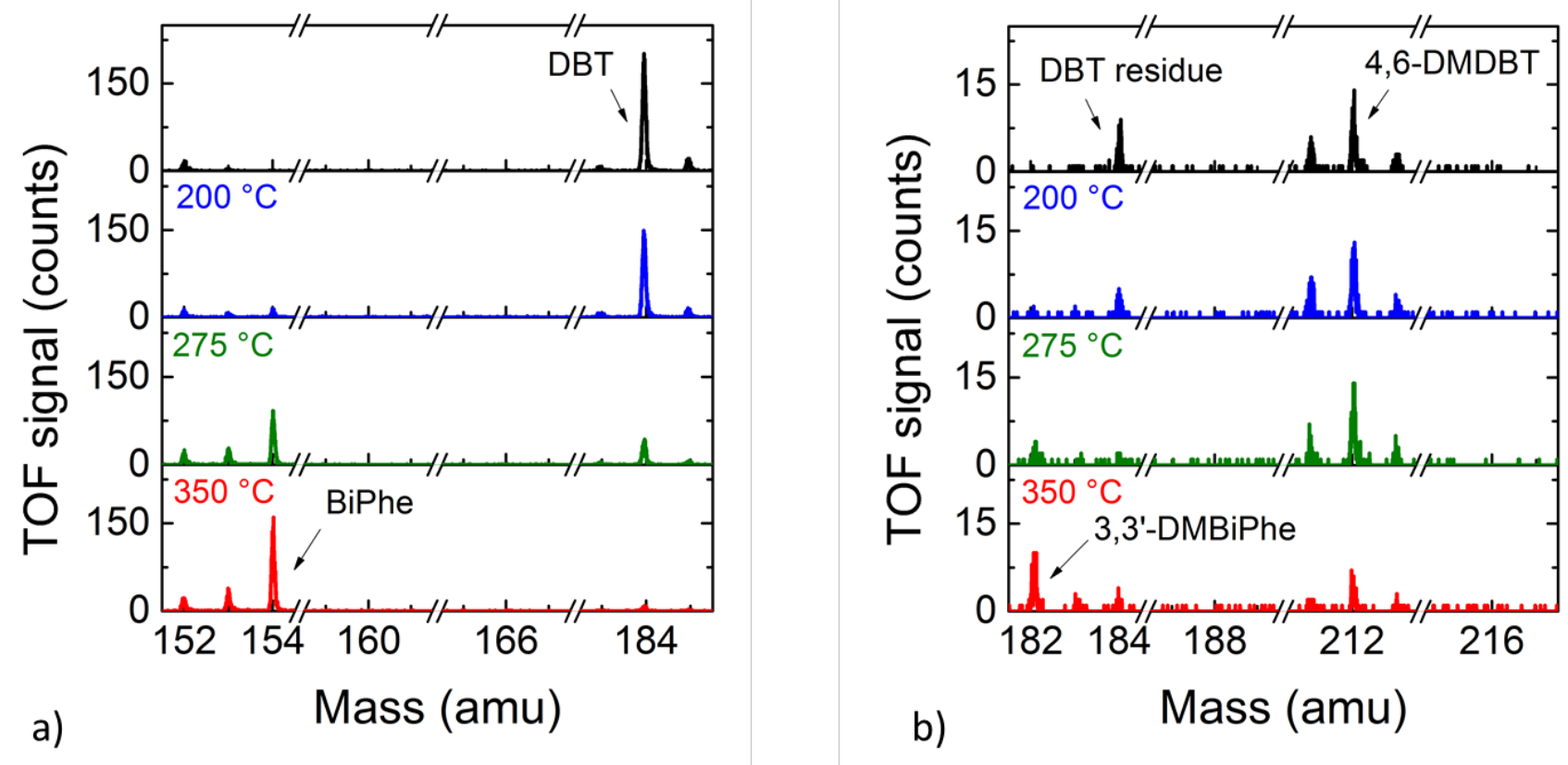

Figure 4. HDS of a) DBT into BiPhe and b) 4,6-DMDBT into 3,3'-DMBiPhe. Black scans were obtained before addition of $\mathrm{H}_{2}$, blue scans at $200{ }^{\circ} \mathrm{C}$, green scans at $275^{\circ} \mathrm{C}$ and red scans at $350{ }^{\circ} \mathrm{C}$.

As can be seen in Figure 4, there are no indications of BiPhe nor 3,3'-DMBiPhe before introducing $\mathrm{H}_{2}$ into the system (black scan). In Figure 4a it is seen how DBT is slowly converted into BiPhe as $\mathrm{H}_{2}$ is added and the temperature increased to $200{ }^{\circ} \mathrm{C}$. Furthermore, at $350{ }^{\circ} \mathrm{C}$ full conversion is approached and almost no DBT is left.

In the uppermost spectrum of 4,6-DMDBT (Figure 4b) small residues of DBT are present. This is caused by DBT deposits inside the tubing, which are released with the increase in temperature when switching from DBT to 4,6-DMDBT. Hence, is difficult to avoid with the current setup construction enabling back-to-back measurements of DBT and 4,6-DMDBT.

What can also easily be seen from the spectra in Figure $4 \mathrm{~b}$ is that the peak intensities are significantly lower than the ones observed in Figure 4a. This can be explained by the low 
partial pressure of 4,6-DMDBT inside the $\mu$-reactor, which was limited by the heat resistance of the components inside the containment volume. However, it is still evident that 4,6DMDBT is successfully converted into 3,3-DMBiPhe.

In order to follow the evolution of the relevant peaks as a function of time and reaction temperature, data is presented as the integrated peak area of specified base peaks in each scan recorded at every temperature step: DBT $(m / z=184)$ and BiPhe $(m / z=154)$ (Figure 5a) and for 4,6-DMDBT $(m / z=212)$ and 3,3'-DMBiPhe $(m / z=182)$ (Figure 5b), respectively.
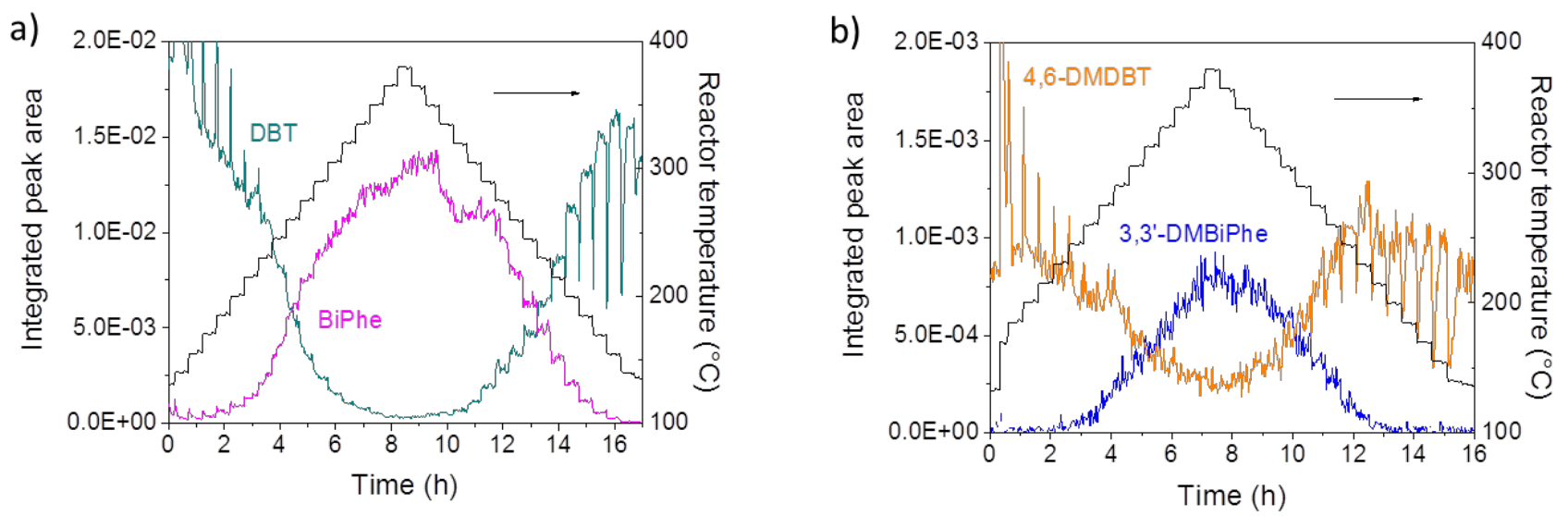

Figure 5. a) Integrated peak areas of DBT and BiPhe as a function of time and temperature. b) Integrated peak areas of 4,6DMDBT and 3,3'-DMBiPhe as a function of time and temperature.

The left y-axes show the integrated peak areas, whereas the right y-axes show the reaction temperature. As seen from both plots in Figure 5, significant spikes are present in the reactant signals at all temperature steps below $250{ }^{\circ} \mathrm{C}$. This is attributed to desorption and adsorption of species from the catalyst surface during the upward and downward temperature ramp, respectively. This means that the partial pressures of the reactants are transiently higher than what can be estimated from the compound source temperatures.

For the conversion of DBT (Figure 5a) it results in temporary increases in the BiPhe signal even at low temperatures. Another artefact is the shoulder observed in the BiPhe signal after approximately ten hours of measurements at a temperature of $335^{\circ} \mathrm{C}$, This is caused by an 
unintended decrease in the DBT source temperature leading to a lower amount of DBT present in the inlet gas.

For the plot in Figure 5b the increase in 3,3'-DMBiPhe follows the decrease in 4,6-DMDBT from temperatures above $250^{\circ} \mathrm{C}$.

Defining the initial DBT and 4,6-DMDBT level is difficult due to the degassing at temperatures below $250^{\circ} \mathrm{C}$, so conversion, $X$, was estimated as the ratio between the product and the sum of reactant and product. Furthermore, an apparatus specific sensitivity factor was applied, resulting in equation

$$
X=\frac{x A_{B i P h e / 3,3 \prime-D M B i P h e}}{x A_{\text {BiPhe } / 3,3 \prime-D M B i P h e}+A_{D B T / 4,6-D M D B T}}
$$

Where $x$ is the sensitivity factor and $A$ is the integrated peak area of the specified base peaks.

Figure 6 shows the conversion of both DBT and 4,6-DMDBT. Each data point represents the average conversion and the standard deviation calculated for all TOF scans recorded at each temperature step. It is evident that the HDS of DBT proceeds much faster and reaches full conversion at $380^{\circ} \mathrm{C}$, whereas the conversion of 4,6-DMDBT has larger standard deviations, and peaks at $80 \%$ at $380{ }^{\circ} \mathrm{C}$. 


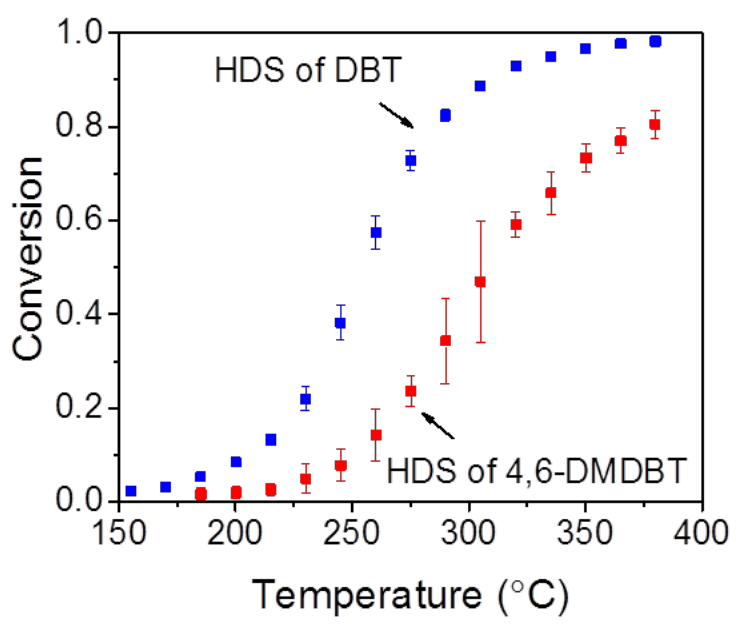

Figure 6. Conversion of DBT and 4,6-DMDBT, respectively. Each data point represents the average conversion and the standard deviation calculated for all TOF scans recorded at each temperature step.

From literature, there does not seem to be a general agreement on the preferred reaction pathway in the HDS of 4,6-DMDBT over Pt nanoparticles. Niquille-Röthlisberger et al. ${ }^{52}$ studied the HDS of 4,6-DMDBT over $2 \mathrm{~nm}$ alumina-supported Pt nanoparticles at 50 bar and $300{ }^{\circ} \mathrm{C}$ and found that the HYD pathway prevails. Contrary to this, other studies have shown that the DDS pathway is dominating for the HDS of both DBT and 4,6-DMDBT under similar conditions ${ }^{53}$. In the industrial HDS reaction the minimum $\mathrm{H}_{2}$ pressure employed is 20 bar $^{4}$. It is possible that the total pressure of 800 mbar applied in this study is the main reason for only observing the DDS products, BiPhe and 3,3'-DMBiPhe, since the HYD pathway requires 2.5 times more $\mathrm{H}_{2}$ to form $\mathrm{CHB}$ and 3,3'-DMCHB, respectively (see Figure 2). This is supported by the findings of Haji et al. ${ }^{54}$ where HDS of 4,6-DMDBT was performed at atmospheric pressure.

The steric hindrance observed in 4,6-DMDBT is still the important threshold to overcome in the production of ULSD. This study bridges the gap between structural characterization of model catalysts and their related activity. For the industrially relevant $\mathrm{MoS}_{2}$ based HDS catalyst we will in the future expand this study and use this setup to readily test the relative 
activity between DBT and 4,6-DMDBT and use it as a guide towards nano-engineering new $\mathrm{MoS}_{2}$ structures that expose more active sites and enhance the catalytic activity ${ }^{53}$.

\section{CONCLUSION}

In this work we have shown how the refractory sulfur containing model compounds DBT and 4,6-DMDBT can be successfully desulfurized through gas phase HDS in a silicon-based $\mu$ reactor at 800 mbar over Pt nanoparticles. The entire reaction gas volume was analyzed in a TOF-MS, enabling high sensitivity and high mass resolution. We have demonstrated that the configuration of our dedicated setup allows for back-to-back measurements between the two model compounds, and immediately establish the most prevailing reaction pathway (HYD or DDS). We have shown that even minute amounts of Pt nanoparticles show high activity in both the HDS of DBT and 4,6-DMDBT. Only the DDS products were observed, which is not surprising. Under industrially relevant conditions, it is observed that DBT favors the DDS pathway, whereas 4,6-DMDBT favors the HYD pathway. Since the HYD pathway is highly dependent on the $\mathrm{H}_{2}$ pressure even at industrially relevant pressures, the effect must be even more pronounced at low pressures, which can be assumed to be the reason why no HYD products are formed. Our setup bridges the gap between structural characterization of relevant catalytic model systems and their activity and the plan is to study if $\mathrm{MoS}_{2}$ nanoparticles could be designed to have higher activities. 


\section{ASSOCIATED CONTENT}

\section{Supporting Information}

The following files are available free of charge.

TOF scans of the HDS of DBT and 4,6-DMDBT at 200, 275 and $350{ }^{\circ} \mathrm{C}$ (PDF)

\section{AUTHOR INFORMATION}

\section{Corresponding Author}

*Corresponding author: ibchork@fysik.dtu.dk

\section{ACKNOWLEDGMENTS}

The authors acknowledge helpful discussions with Dr. Michael Brorson, Haldor Topsøe A/S. This work was supported by a research grant (HYDECAT) from the Danish Research Council - Technology and Production. 


\section{References}

(1) Song, C. An Overview of New Approaches to Deep Desulfurization for Ultra-Clean Gasoline, Diesel Fuel and Jet Fuel. Catal. Today 2003, 86 (1-4), 211-263.

(2) Stanislaus, A.; Marafi, A.; Rana, M. S. Recent Advances in the Science and Technology of Ultra Low Sulfur Diesel (ULSD) Production. Catal. Today 2010, 153 (1-2), 1-68.

(3) Qusro, Q.; Massoth, F. E. Comparison of High and Low Pressure HDS Activities for Mo/Al2O3 Catalysts; 1987; Vol. 29.

(4) Topsøe, H.; Clausen, B. S.; Massoth, F. E. Hydrotreating Catalysis Science and Technology; Anderson, J. R., Boudart, M., Eds.; Springer Verlag, 1996.

(5) Bensch, W. Comprehensive Inorganic Chemistry II; Elsevier, 2013.

(6) Topsøe, H. H.; Knudsen, K. G.; Byskov, L. S.; Nørskov, J. K.; Clausen, B. S. Advances in Deep Desulfurization. In Science and Technology in Catalysis; 1998; pp $13-22$.

(7) Srivastava, V. C. An Evaluation of Desulfurization Technologies for Sulfur Removal from Liquid Fuels. RSC Adv. 2012, 2 (3), 759.

(8) Shafi, R.; Hutchings, G. J. Hydrodesulfurization of Hindered Dibenzothiophenes: An Overview. Catal. Today 2000, 59 (3-4), 423-442.

(9) Kibsgaard, J.; Tuxen, A.; Knudsen, K. .; Brorson, M.; Topsøe, H. H.; Laegsgaard, E.; Lauritsen, J. V.; Besenbacher, F. Comparative Atomic-Scale Analysis of Promotional Effects by Late 3d-Transition Metals in MoS 2 Hydrotreating Catalysts. J. Catal. 2010, 272, 195-203. 
(10) Kilanowski, D. R.; Teeuwen, H.; de Beer, V. H. J.; Gates, B. C.; Schuit, G. C. A.; Kwart, H. Hydrodesulfurization of Thiophene, Benzothiophene, Dibenzothiophene, and Related Compounds Catalyzed by Sulfided CoO-MoO3/y-Al2O3: Low-Pressure Reactivity Studies. J. Catal. 1978, 55 (2), 129-137.

(11) Kabe, T.; Ishihara, A.; Zhang, Q. Deep Desulfurization of Light Oil. Part 2: Hydrodesulfurization of Dibenzothiophene, 4- Methyldibenzothiophene and 4,6Dimethyldibenzothiophene. Appl. Catal. A Gen. 1993, 97.

(12) Kabe, T.; Ishihara, A.; Tajima, H. Hydrodesulfurization of Sulfur-Containing Polyaromatic Compounds in Light Oil. Ind. Eng. Chem. Res. 1992, 31, 1577-1580.

(13) Egorova, M.; Prins, R. Hydrodesulfurization of Dibenzothiophene and 4,6Dimethyldibenzothiophene over Sulfided NiMo/ $\gamma-\mathrm{Al} 2 \mathrm{O} 3, \mathrm{CoMo} / \gamma-\mathrm{Al} 2 \mathrm{O} 3$, and $\mathrm{Mo} / \gamma-$ Al2O3 Catalysts. J. Catal. 2004, 225, 417-427.

(14) Grønborg, S. S.; Šaric, M.; Moses, P. G.; Rossmeisl, J.; Lauritsen, J. V. Atomic Scale Analysis of Sterical Effects in the Adsorption of 4,6-Dimethyldibenzothiophene on a CoMoS Hydrotreating Catalyst. J. Catal. 2016, 344, 121-128.

(15) Egorova, M.; Prins, R. The Role of Ni and Co Promoters in the Simultaneous HDS of Dibenzothiophene and HDN of Amines over Mo/ $\gamma$-Al 2 O 3 Catalysts. J. Catal. 2006, 241, 162-172.

(16) Knudsen, K. G.; Cooper, B. H.; Topsøe, H. Catalyst and Process Technologies for Ultra Low Sulfur Diesel. Appl. Catal. A Gen. 1999, 189, 205-215.

(17) Ertl, G.; Freund, H.-J. Catalysis and Surface Science. Phys. Today 1999, 52 (1), 32-38.

(18) Palmer, R. E.; Pratontep, S.; Boyen, H.-G. Nanostructured Surfaces from Size-Selected 
Clusters. Nat. Mater. 2003, 2, 443-448.

(19) Sattler, K.; Muhlbach, J.; Recknagel, E. Generation of Metal Clusters Containing from 2 to 500 Atoms. Phys. Rev. Lett. 1980, 45 (10), 821-824.

(20) Dietz, T. G.; Duncan, M. A.; Powers, D. E.; Smalley, R. E. Laser Production of Supersonic Metal Cluster Beams Laser Production of Supersonic Metal Cluster Beams a ). J. Chem. Phys. 1981, 74, 6511-41101.

(21) Borgna, A.; Hensen, E. J. M.; Van Veen, J. A. R.; Niemantsverdriet, J. W. Intrinsic Kinetics of Thiophene Hydrodesulfurization on a Sulfided NiMo/SiO 2 Planar Model Catalyst. J. Catal. 2004, 221, 541-548.

(22) De Jong, A. M.; De Beer, V. H. J.; Rob Van Veen, J. A.; Niemantsverdriet, H. Surface Science Model of a Working Cobalt-Promoted Molybdenum Sulfide Hydrodesulfurization Catalyst: Characterization and Reactivity. J. Phys. Chem. 1996, 100, 17722-17724.

(23) Kishan, G.; van Veen, J. A. .; Niemantsverdriet, J. W. Realistic Surface Science Models of Hydrodesulfurization Catalysts on Planar Thin-Film Supports: The Role of Chelating Agents in the Preparation of CoW/SiO 2 Catalysts. Top. Catal. 2004, 29, 103-110.

(24) Böhme, D. K.; Schwarz, H. Gas-Phase Catalysis by Atomic and Cluster Metal Ions: The Ultimate Single-Site Catalysts. Angew. Chemie - Int. Ed. 2005, 44 (16), 23362354.

(25) Jacobs, P. W.; Somorjai, G. A. Conversion of Heterogeneous Catalysis from Art to Science: The Surface Science of Heterogeneous Catalysis. J. Mol. Catal. A Chem. 1998, 131, 5-18. 
(26) Tuxen, A. K.; Füchtbauer, H. G.; Temel, B.; Hinnemann, B.; Topsøe, H.; Knudsen, K. G.; Besenbacher, F.; Lauritsen, J. V. Atomic-Scale Insight into Adsorption of Sterically Hindered Dibenzothiophenes on MoS2 and Co-Mo-S Hydrotreating Catalysts. J. Catal. 2012, 295, 146-154.

(27) Tuxen, A. K.; Kibsgaard, J.; Gøbel, H.; Laegsgaard, E.; Topsøe, H. H.; Lauritsen, J. V.; Besenbacher, F. Size Threshold in the Dibenzothiophene Adsorption on MoS 2 Nanoclusters. ACS Nano 2010, 4 (8), 4677-4682.

(28) Lauritsen, J. V.; Helveg, S.; Lægsgaard, E.; Stensgaard, I.; Clausen, B. S.; Topsøe, H. H.; Besenbacher, F. Atomic-Scale Structure of Co-Mo-S Nanoclusters in Hydrotreating Catalysts; Academic Press, 2001; Vol. 197.

(29) Lauritsen, J. V.; Kibsgaard, J.; Olesen, G. H.; Moses, P. G.; Hinnemann, B.; Helveg, S.; Nørskov, J. K.; Clausen, B. S.; Topsøe, H. H.; Lægsgaard, E.; et al. Location and Coordination of Promoter Atoms in Co- and Ni-Promoted MoS2-Based Hydrotreating Catalysts. J. Catal. 2007, 249 (2), 220-233.

(30) Daage, M.; Chianelli, R. R.; Ruppert, A. F. Structure-Function Relations in Layered Transition Metal Sulfide Catalysts. In New Frontiers in Catalysis; 1993; pp 571-584.

(31) Helveg, S.; Lauritsen, J. V.; Lægsgaard, E.; Stensgaard, I.; Nørskov, J. K.; Clausen, B. S.; Topsøe, H.; Besenbacher, F. Atomic-Scale Structure of Single-Layer MoS 2 Nanoclusters. Phys. Rev. Lett. 2000, 84 (5), 951-954.

(32) Bollinger, M.; Jacobsen, K.; Nørskov, J. Atomic and Electronic Structure of MoS2 Nanoparticles. Phys. Rev. B 2003, 67 (8), 85410.

(33) Bruix, A.; Füchtbauer, H. G.; Tuxen, A. K.; Walton, A. S.; Andersen, M.; Porsgaard, S.; Besenbacher, F.; Hammer, B.; Lauritsen, J. V; Füchtbauer, H. G.; et al. In Situ 
Detection of Active Edge Sites in Single-Layer MoS 2 Catalysts. 2015, No. 9, 93229330.

(34) Zhu, Y.; Ramasse, Q. M.; Brorson, M.; Moses, P. G.; Hansen, L. P.; Kisielowski, C. F.; Helveg, S. Visualizing the Stoichiometry of Industrial-Style Co-Mo-S Catalysts with Single-Atom Sensitivity. Angew. Chem. Int. Ed. Engl. 2014, 53 (40), 1072310727.

(35) Baubet, B.; Girleanu, M.; Gay, A. S.; Taleb, A. L.; Moreaud, M.; Wahl, F.; Delattre, V.; Devers, E.; Hugon, A.; Ersen, O.; et al. Quantitative Two-Dimensional (2D) Morphology-Selectivity Relationship of CoMoS Nanolayers: A Combined HighResolution High-Angle Annular Dark Field Scanning Transmission Electron Microscopy (HR HAADF-STEM) and Density Functional Theory (DFT) Study. ACS Catal. 2016, 6 (2).

(36) Bartsch, R.; Tanielian, C. Hydrodesulfurization I. Hydrogenolysis of Benzothiophene and Dibenzothiophene over CoO-MoO3-Al203 Catalyst. J. Catal. 1974, 35, 353-358.

(37) Houalla, M.; Nag, N. K.; Sapre, A. V.; Broderick, D. H.; Gates, B. C. Hydrodesulfurization of Dibenzothiophene Catalyzed by Sulfided CoO-MoO3 YAl2O3: The Reaction Network. ACS Div. Fuel Chem. Prepr. 1978, 24, 1015-1021.

(38) Whitehurst, D. D.; Isoda, T.; Mochida, I. Present State of the Art and Future Challenges in the Hydrodesulfurization of Polyaromatic Sulfur Compounds. Adv. Catal. 1998, 42, 345-471.

(39) Singhal, G. H.; Espino, R. L.; Sobel, J. E.; Huff, G. A. . Hydrodesulfurization of Sulfur Heterocyclic Compounds: Kinetics of Dibenzothiophene. J. Catal. 1981, 67 (2), 457468. 
(40) Li, X.; Wang, A.; Egorova, M.; Prins, R. Kinetics of the HDS of 4,6-

Dimethyldibenzothiophene and Its Hydrogenated Intermediates over Sulfided Mo and NiMo on $\gamma$-Al 2 O 3. J. Catal. 2007, 250, 283-293.

(41) Prins, R.; Egorova, M.; Röthlisberger, A.; Zhao, Y.; Sivasankar, N.; Kukula, P. Mechanisms of Hydrodesulfurization and Hydrodenitrogenation. Catal. Today 2006, 111 (1-2), 84-93.

(42) Girgis, M. J.; Gates, B. C. Reactivities, Reaction Networks, and Kinetics in HighPressure Catalytic Hydroprocessing. Ind. Eng. Chem. Res. 1991, 30 (9), 2021-2058.

(43) Edwards, D. R.; Prausnitz, J. M. Vapor Pressures of Some Sulfur-Containing, CoalRelated Compounds. J. Chem. Eng. Data 1981, 26 (2), 121-124.

(44) https://comptox.epa.gov/dashboard/. 4,6-Dimethyldibenzothiophene.

(45) Henriksen, T. R.; Olsen, J. L.; Vesborg, P.; Chorkendorff, I.; Hansen, O. Highly Sensitive Silicon Microreactor for Catalyst Testing. Rev. Sci. Instrum. 2009, 80 (12), 124101.

(46) Kemppainen, E.; Bodin, A.; Sebok, B.; Pedersen, T.; Seger, B.; Mei, B.; Bae, D.; Vesborg, P. C. K.; Halme, J.; Hansen, O.; et al. Scalability and Feasibility of Photoelectrochemical H2 Evolution: The Ultimate Limit of Pt Nanoparticle as an HER Catalyst. Energy Environ. Sci. 2015, 8 (10), 2991-2999.

(47) Henriksen, T. R. Silicon Microreactors for Measurements of Catalytic Activity, 2010.

(48) Andersen, T.; Jensen, R.; Christensen, M. K.; Pedersen, T.; Hansen, O.; Chorkendorff, I. High Mass Resolution Time of Flight Mass Spectrometer for Measuring Products in Heterogeneous Catalysis in Highly Sensitive Microreactors. Rev. Sci. Instrum. 2012, 
83 (7), 75105.

(49) Issendorff, B. Von; Palmer, R. E. A New High Transmission Infinite Range Mass Selector for Cluster and Nanoparticle Beams. 1999, 70 (12), 4497-4501.

(50) Perez-Alonso, F. J.; McCarthy, D. N.; Nierhoff, A.; Hernandez-Fernandez, P.; Strebel, C.; Stephens, I. E. L.; Nielsen, J. H.; Chorkendorff, I. The Effect of Size on the Oxygen Electroreduction Activity of Mass-Selected Platinum Nanoparticles. Angew. Chemie Int. Ed. 2012, 51 (19), 4641-4643.

(51) Vesborg, P. C. K.; Olsen, J. L.; Henriksen, T. R.; Chorkendorff, I.; Hansen, O. Note: Anodic Bonding with Cooling of Heat-Sensitive Areas. Rev. Sci. Instrum. 2010, 81 (1).

(52) Niquille-Röthlisberger, A.; Prins, R. Hydrodesulfurization of 4,6Dimethyldibenzothiophene and Dibenzothiophene over Alumina-Supported Pt, Pd, and Pt-Pd Catalysts. J. Catal. 2006, 242, 207-216.

(53) Castillo-Araiza, C. O.; Chávez, G.; Dutta, A.; de los Reyes, J. A.; Nuñez, S.; GarcíaMartínez, J. C. Role of Pt-Pd/ $\gamma-A 12 \mathrm{O} 3$ on the HDS of 4,6-DMBT: Kinetic Modeling \& Contribution Analysis. Fuel Process. Technol. 2015, 132, 164-172.

(54) Haji, S.; Zhang, Y.; Erkey, C. Atmospheric Hydrodesulfurization of Diesel Fuel Using Pt/Al2O3 Catalysts Prepared by Supercritical Deposition for Fuel Cell Applications. Appl. Catal. A Gen. 2010, 374 (1-2), 1-10.

(53) Bodin A, Christoffersen A. N., Elkjær C. F., Kibsgaard J, Helveg S, Chorkendorff I. Engineering Ni-Mo-S Nanoparticles for Hydrodesulfurization. In preparation. 
Table of Contents Image

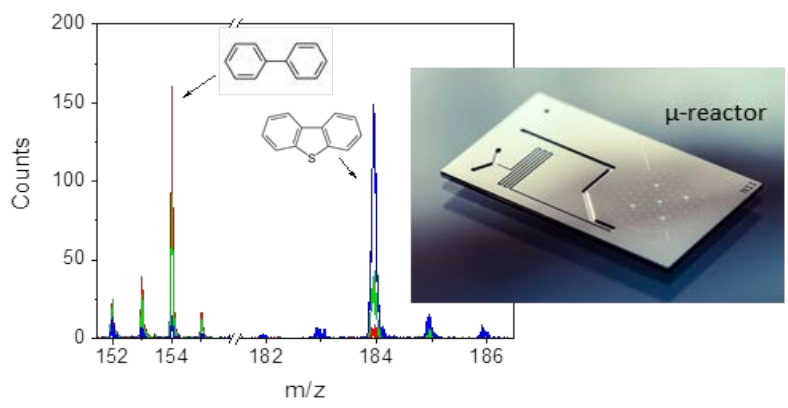

